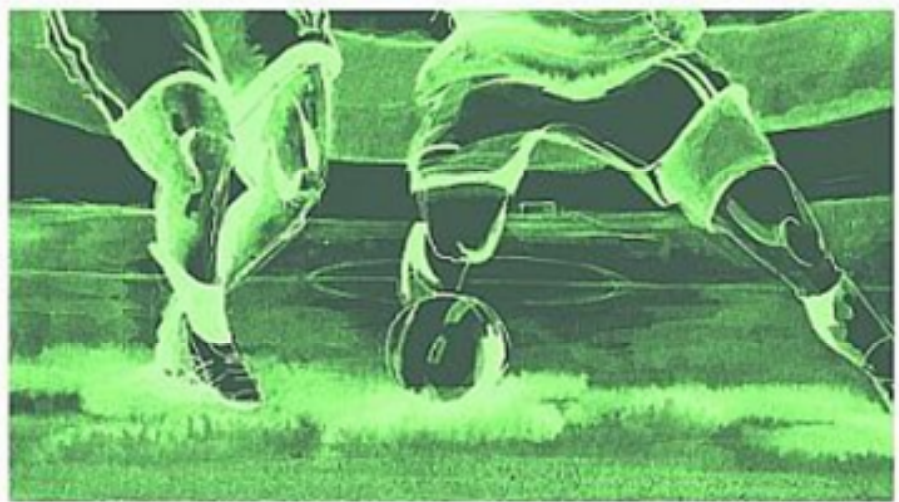

Ilustração Mário Vinícius Júnior da Silva

\title{
Ia literatura hecha pelota: primer acercamiento a los cuentos de fútbol argentino
}

\section{Javier E. Sánchez}

Javier Enrique Sánchez é jornalista esportivo e professor de Letras, formado na Universidad Nacional de Mar del Plata, onde é vinculado à cátedra Literatura Argentina II e participante do grupo de pesquisa "Cultura e politica na Argentina". Professor no curso de Técnico Superior em Segurança Pública, com orientação em polícia distrital, pertencente ao Ministério de Segurança da Província de Buenos Aires.

\section{Resumen}

Este texto es el primer acercamiento crítico del autor a los cuentos de fútbol argentino, donde se propone la existencia de un género muy particular que se construye en el intesticio de la cultura popular y la alta literatura.

Palabras clave: fútbol, tradición, oralidad.

Juan José Sebreli en La era del fútbol marca que la sociedad argentina se ha acostumbrado a la ilegalidad y que en su obra literaria más reconocida su héroe mayor es un cuchillero, un 
fuera de la ley. También señala que los juegos son un espejo de la sociedad y que el fútbol, al igual que el truco, está dominado por el engaño (el amague, el despiste, la finta).(1) Si los cuentos de fútbol se sirven del mismo deporte al que hace referencia sebreli no es de extrañar que amaguen, que despisten, aunque en este caso, literariamente hablando. Son conscientes de su lugar desplazado en el panorama literario y no encuentran otra forma de acceso que la que Ricardo Piglia ve en Roberto Arlt: el robo de libros en la biblioteca. (2)

La literatura de la pelota, forma en que pueden ser englobados los cuentos de fútbol, a tono con lo deportivo juega un partido propio con la "alta literatura". Confrontación en la que va a estar en juego la posibilidad de utilizar un código (propio de la tradición escrita) y de re-utilizar en los cuentos de fútbol una tradición literaria que "supuestamente" tendría que serle ajena.

Los escritores dan voz (escrita) a quienes se desenvuelven mayoritariamente en un mundo oral y en ese trabajo de pasaje introducen, reinterpretando y reutilizando, la tradición de la literatura argentina. Tal vez las influencias más notorias sean las de la gauchesca, la de Borges y la del tango. Pero, además, es muy notoria e importante la influencia de otros textos canónicos de la literatura argentina, por ejemplo: Facundo de Sarmiento o "Esa mujer" de Walsh.

La gauchesca tiene como una de sus marcas distintivas el diálogo, que une a dos o tres amigos pertenecientes a la misma extracción social, para intercambiar cuitas. A menudo los cuentos de fútbol copian este esquema, por ejemplo: "Escenas de la vida deportiva" de Roberto Fontanarrosa.

Lo que en la gauchesca es un pasaje, según Ángel Rama, que va del protagonismo del gaucho, luego pasa por ser testigos y finaliza con la mera contemplación de espectáculos, en el fútbol es una mezcla que va de los futboleros jugando en un potrero o en una cancha de papi, de espectadores en la cancha alentando o de espectadores no presenciales por medio de la televisión o la radio.

Así como en la gauchesca los autores pertenecieron a niveles de cultura superiores a los de personajes y ambientes utilizados en sus obras, en la literatura de la pelota sucede lo mismo. Ambos sistemas funcionan desde un nivel culto proyectándose hacia abajo (siguiendo la idea de Ángel Rama).

Por el lado de la influencia de Borges se puede marcar la recurrencia en la aparición de personajes que en cierto momento de la narración enfrentan su destino y recién ante ese hecho descubren su verdadera identidad y a partir de esto 
encuentran la muerte ("El hincha" de Giardinelli, "Ver o jugar" de Marcos Mayer, "La música de los domingos" de Liliana Heker, "Campitos" de Juan Sasturain).

Además, principalmente, comparten con Borges lo que sarlo denominó "la creación de una tradición cultural", característica que ya marcamos más arriba.

La relación con el tango es muy notoria en cuanto a la recurrencia a un tono nostálgico que da cuenta del paso del tiempo y de algunas ausencias.(3) La pena por el paso del tiempo, que en el tango se hacía visible entre otras cosas en la decadencia física de la mujer, se repite en los cuentos de fútbol sufrida por los hombres en tanto que jugadores. En los dos casos notamos al cuerpo como medio de trabajo y la decadencia corporal va acompañada de un cambio en la valoración social del personaje, esto tiene que ver con las relaciones entre prestigio-fama-opinión. Lo que en el tango es un lamento por la desaparición del malevaje y el paso de la milonguera de arrabal al cabaret del centro, en estos cuentos es lamento por la desaparición del potrero de barrio y del jugador de potrero. La solución en los dos casos es similar: valoración y rememoración del pasado y vuelta al barrio (solución utópica puesto que en ambos casos ese barrio ya desapareció). Un cuento ejemplar sobre esta influencia es el de Eduardo Sacheri "Me van a tener que disculpar" en el que el narrador se enfrenta al tiempo por deteriorar al ídolo-mito (Diego Maradona). La función de Maradona como personaje evocado marca la similitud que hay con la añoranza de la mujer en el tango tal como la ve Ernesto Sábato en "Tango, discusión y clave", quien ve en la añoranza de la mujer la nostalgia de la comunión y el amor; no la presencia de un instrumento de la lujuria(4); así como la añoranza del ídolo máximo es nostalgia por la belleza que desplegaba en el juego y no solamente por los resultados obtenidos. También se puede nombrar al Rosendo Rebottaro de Dolina, al "Bordadora" Zatti de Humberto Constantini, "De chilena" de Sacheri y "La música de los domingos" de Liliana Heker como personajes y cuentos de tono marcadamente tangueros.

Pero no solamente se tomarán rasgos gauchescos, borgeanos y tangueros sino que haciendo uso ampliamente de la tradición aparecerán hibridaciones genéricas que van a cruzar la modulación oral dentro de un marco genérico establecido tratando una temática "futbolística". Podríamos caracterizar, entonces, ciertos cuentos a partir de una pirámide que se forma con la oralidad y el fútbol como tema en la base y un género (que puede variar) en la cúspide. 


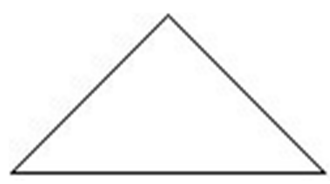

Oralidad

Fútbol

La cuestión temática y la modulación oral son constantes mientras que la macroestructura es variable. A partir de esta variedad genérica encontramos una diversidad muy amplia en cuanto a las características de los textos y que es lo que hace que se dude sobre la clasificación "cuento de fútbol".

Entro los géneros que se mezclan podemos contar la narrativa histórica ("El hincha" de Mempo Giardinelli), las memorias autojustificatorias o confesiones ("Fantasía española" de Marcelo Cohen), la ciencia ficción ("Dieguito" de José Pablo Feinmann), la autobiografía ("Insai izquierdo" de Humberto Constantini, "Gallardo Pérez, referí" de Osvaldo Soriano), los relatos enmarcados ("Apuntes del fútbol en Flores" de Alejandro Dolina), el relato meta-ficcional ("Milagro en Parque Chas" de Inés Fernández Moreno) y el relato costumbrista ("Escenas de la vida deportiva" de Roberto Fontanarrosa), entre otros.

\section{Breve análisis de algunos cuentos de fútbol}

Un cuento notable por la utilización que realiza de la tradición literaria es "El hincha" de Mempo Giardinelli. A partir de un epígrafe de tono realista que contextualiza la situación se cuenta la última tarde de Amaro Fuentes, y de alguna manera toda su vida. Fuentes es un personaje común que debe su vida al fútbol. Al estilo gauchesco y tanguero, aunque sin la forma dialogada del primero, rememora un tiempo pasado que fue mejor (los potreros que están desapareciendo, su pasado como promisorio futbolista). En los diálogos que aparecen se muestra un registro popular-futbolero. Tiene algunos rasgos del Martín Fierro en cuanto a la imposibilidad de cambiar su destino y la tendencia a soportar la adversidad. También en la línea de la gauchesca hay una valoración de lo local por sobre lo nacional, simbolizado a través de la mayor valoración del club por sobre la Selección Nacional. El protagonista va a mostrar un primer cambio en la personalidad después del viaje a la capital para ver a Vélez, gracias al viaje se convierte en un sujeto experiente y con posibilidad de hablar con fundamento porque "vio", viaje que recuerde el del pollo a ver el espectáculo a la capital. También toma de 
la obra de Del Campo el valor de la amistad que demuestran aquí los amigos de Amaro Fuentes que se alegran de la victoria de su equipo. El título que consigue Vélez le pone un final feliz a la obra cumpliendo el deseo del protagonista de verlo campeón, aunque en medio de los festejos el corazón del protagonista, poco a acostumbrado a las alegrías, deje de funcionar. Amaro es un personaje de vida gris que ya no contaba con "salir de pobre", un resultado deportivo es el que cambiará su vida y abrirá la puerta a la muerte.

Otro cuento en el que vale la pena detenerse es "Escenas de la vida deportiva" de Roberto Fontanarrosa. Aquí juegan en primer plano el coro de voces "bajas" de los jugadores-amigos que juegan por gusto. Se pone en juego una descripción "realista" de la problemática del jugador aficionado: reserva de la cancha, falta de pelota, la elongación precompetitiva, la falta de jugadores, del rival, la rotura del cordón del botín, la pelota desinflada y el pinchazo al tratar de inflarla. La oralidad en estos personajes se relaciona directamente con la sexualidad, toda una serie de alusiones sexuales se despliega en la antesala del juego. Pareciera que el tratamiento oral de la sexualidad desacralizadamente fuera el juego sexual previo antes del máximo goce del sujeto: el juego. El humor que rodea el espacio del fútbol es bajo, corporal y sexual, siempre manteniendo un tono machista en el que la forma privilegiada de atacar al otro es mostrar su lado femenino. Los personajes son tipos definidos (el gordo que va al arco, el defensor rústico, el morfón, el que no trae la pelota, el que de metido pincha la pelota, etc.) y no muestran ninguna evolución.

Para ejemplificar el tema ya mencionado de la reutilización de la tradición nacional viene muy bien el cuento "Campitos" de Juan Sasturain. Aquí desde el epígrafe mismo se va a poner en juego esta doble articulación "fútbol/tradición cultural" mediante la aparición de dos citas. Nada ingenuamente las citas son de los considerados "grandes maestros" en su materia: Domingo F. Sarmiento y Dante Panzeri. Sasturain articula las dos problemáticas marcadas por los maestros y a partir de ahí construye un cuento notable. "El mal que aqueja a la República Argentina es la extensión" y "Al fútbol argentino le faltan tres cosas: dirigentes, decencia y wines" son la ideas negativas sobre la Argentina que disparan la historia de Campitos. Ingeniero agrónomo de vida normal hasta que en un instante una iluminación le cambia la vida y lo pone a las puertas de cambiar la historia: comprende que el surgimiento de valores futbolísticos está determinado por las condiciones geográficas. Idéntico al afán sarmientino Campodónico ve que se puede civilizar (mediante el estudio sistemático) la barbarie de una extensión que se desconoce. Aquí también, al igual que en "El hincha" de Giardinelli ingresan elementos de la historia argentina: el peronismo y la 
muerte de Evita son los más reconocibles. Y de alguna manera se relaciona también con el relato mítico por la forma de derivar el trabajo del ingeniero agrónomo en la creación del "semillero", como una de las instituciones a tener en cuenta alrededor del fútbol.

Después de este breve repaso de carácter general al principio y particular hacia el final parece prevalecer la importancia de una oralidad que resulta definitoria para clasificar los cuentos y para valorarlos. Existe una relación igualitaria entre la voz oral y la idea de lo popular (entendido simplemente como no elitista). Aquí radica la diferencia entre el narrador de Bustos Domecq y el de Osvaldo Soriano, aunque los dos puedan remitirse identitariamente a los propios autores en su carácter de letrados uno escribe cuentos de fútbol y el otro no. Aunque Fontanarrosa juegue a fondo con el molde y haga, extrañamiento mediante, que el héroe-narrador sea un jugador de metegol esa voz es inconfundible. Hay una voz que hace a los cuentos de fútbol, una voz que hace a la literatura pelota.

\section{Los no-cuentos de fútbol}

Existen, es verdad, algunos casos de cuentos que aparecen en Cuentos de Fútbol Argentino que debieran no ser considerados "cuentos de fútbol", aunque paradógicamente sí podrían ser catalogados como cuentos hechos pelota, aunque en un principio los denominamos "falsos cuentos de fútbol". Uno de los casos es el de Luisa Valenzuela con su "El mundo es de los inocentes". Este cuento tiene un marcado carácter autorreferencial en el que la narradora-protagonista es una periodista que se ve "obligada" a cubrir a Boca en una final de la Copa Libertadores en Brasil. La periodista no sabe nada de fútbol generando, de esta manera, una mirada externa y presuntamente objetiva del fenómeno deportivo. A partir de este no-saber la protagonista muestra al fútbol como un espacio paralelo al de la realidad, con sus propias reglas. Para describirlo echará mano de una visión carnavalesca del fútbol, donde confunde a un hincha con camiseta y bandera con un disfrazado de comparsa. El cierre del cuento es un poco más que sorprendente, entre surrealista y absurdo: la hinchada de Boca espera el avión en el aeropuerto mientras pasa por delante el equipo de Cruzeiro llevando en brazos la Copa Libertadores ( $i$ ?) que debía dirimirse en un partido en cancha neutral:

"La hinchada de Boca se siente entonces en la peor de sus pesadillas. Enardecida, el odio surcándoles las venas: iVamo a matarlo, vamo! Gritan, y a ese grito de guerra rompen fila para abalanzarse contra la ordenada vanguardia de jugadores de Cruzeiro. Sólo que en el camino se produce la epifanía, y en 
esos pocos metros de brillante piso del Galeao Dios esboza una sonrisa y la furia se trueca en admiración, y llegados al lado de Nelsinho no lo matan, no, simplemente se paran en seco y le preguntan, señalando el pantalón gris que supuestamente es de franela:

-¿Y qué tenés ahí, Nelsinho, un cañón tené en lugar de gamba?

El goleador sonríe al igual que Dios, por unos instantes reina la paz entre los hombres, la hinchada de Boca, disfrazada de Boca, toda de oro y azul y sudor y alguna lágrima, es decir hecha un asco, le arrebata al capitán de Cruzeiro la enorme copa de plata y sale danzando por los pasillos del enorme aeropuerto internacional $[\ldots](5)$

Otro cuento que ejemplifica esta tendencia del no cuento de fútbol es "Esse est percipi" de Bustos Domecq. Presentación de un mundo pesadillesco para la mayoría de los mortales pero paradisíaco para un par de intelectualoides en que el fútbol ha dejado de existir a manos de una farsa mercantilista. Más allá de una cuestión temática la voz de Bustos Domecq nunca llega a hacer creer sobre su conocimiento futbolístico por lo que parece un títere diciendo unos parlamentos que no tienen nada que ver con el personaje que pretende ser.

\section{Resumo}

Este texto é uma primeira aproximação crítica do autor aos contos de futebol argentino, propondo-se a existência de um gênero muito particular que se constrói no interstício da cultura popular e da alta literatura.

Palavras-chave: futebol, tradição, oralidade.

\section{Notas :}

(1) Sebreli, Juan José. La viveza criolla. In: La era del fútbol. Buenos Aires: Sudamericana, 1998. p. 204.

(2) Piglia, Ricardo. Sobre Roberto Arlt. In: Crítica y ficción. Buenos Aires: Seix Barral, 2000. p. 22 .

(3) Ulla, Noemí. Tango, rebelión y nostalgia. Buenos Aires: CEAL, 1982.

(4) Sábato, Ernesto. Sexo. In:Tango. Discusión y clave. Buenos Aires: Losada, 1963.

(5) Valenzuela, Luisa. El mundo es de los inocentes. In: V.V.A.A. Cuentos de Fútbol Argentino, Buenos Aires: Alfaguara, 1998. p. 253. 